\title{
Environmental regulation, upgrading of industrial structure and economic fluctuation
}

Dan Zhang,*, Leyi Chen

Dan Zhang

School of Economics and Trade, Hunan University, Changsha 410079, China;

Leyi Chen

chenleyi1967@163.com,0086-13873108965

*Correspondence: Zhangdan19881123@126.com; $\quad$ Tel.:0086-18674396224

orcid.org/0000-0003-3830-9399 


\title{
Environmental regulation, upgrading of industrial structure and economic fluctuation
}

\section{-an empirical study of dynamic panel threshold based on 35 industries}

\begin{abstract}
This paper utilizes dynamic panel threshold technology to conduct a nonlinear test on the direct effect between environmental regulation and economic fluctuations and the effect of industrial structure upgrading by taking 35 industrial sectors in China from 2003 to 2016 . The research has found that there is an inverted "U" relationship between environmental regulation and economic fluctuations, with the enhancement of environmental regulations, the economic fluctuation increases first and then decreases. The cross-terms of environmental regulation and industrial structure rationalization or industrial structure upgrading are significantly negative, which indicates that the enhancement of environmental regulation is conducive to promoting industrial structure upgrading and reducing the economic fluctuations. While the rationalization factors of industrial structure and advanced industrial structure are significantly negative, indicating that both forms of industrial structure upgrading are conducive to reducing the economic fluctuations. Environmental regulation has technical innovation thresholds for industrial structure upgrading and economic fluctuations, but there are no human capital or FDI thresholds. In the rationalization model of industrial structure, there is a nonlinear " $\mathrm{U}$ " relationship between environmental regulation and economic fluctuations when the proportion of scientific research expenditure is more than $1.35 \%$. With the enhancement of environmental regulation, the economic fluctuation reduces first and then increases, and the corresponding inflection point value is $2.398 \%$ of the environmental regulation level. At the same time, the environmental regulation can indirectly reduce economic fluctuations by pushing down the industrial structure upgrades. In the advanced model of industrial structure, there is a " $U$ " relationship between environmental regulation and economic fluctuation when the proportion of scientific research expenditure is greater than $1.26 \%$. With continuous enhancement of environmental regulation, the economic fluctuation reduces first and then increases. The corresponding inflection point value is $1.78 \%$ of the environmental regulation level, and environmental regulation can indirectly reduce economic fluctuations by promoting the industrial structure at the same time.
\end{abstract}

Keywords: Environmental regulation, Industrial structure upgrade, Economic fluctuation, Dynamic panel threshold

\section{Introduction}

Long-term economic growth and short-term economic fluctuation are the two main themes of macroeconomics. The economy is increasing around the long-term trend, but the short-term fluctuation is normal. Since the 1980s, the information technology revolution has caused profound 
changes in the world industrial structure. The high-end modern service industry has become the driving force of economic development, and its industrial structure has been continuously upgraded, which has contributed greatly to the steady economic development. However, after the financial crisis in 2008, economic stability encountered challenges, increasing the risk of economic fluctuations. Therefore, how to upgrade the industrial structure with stable economic fluctuation and how to reduce economic fluctuation through industrial structure upgrading are important problems that every country encounters.

From the perspective of our country, the current economic society has stepped into the "new normal" of speedy shifts and structural adjustment pains. The report of the 19th National Congress of the CPC noted that construction of an ecological civilization is a millennium plan for the sustainable development of the Chinese nation, and it is necessary to resolutely strike a major offensive war on pollution prevention and control; this reflects the importance attached by the Party and the state to environmental protection. On the one hand, the environmental regulation policy increases an enterprise's cost and profit to a certain extent, impels the enterprise to adjust its production behaviour, and causes an industrial structure adjustment. On the other hand, the upgrading of the industrial structure, as the core tool to coordinate the economy and the environment, affects environmental quality and economic fluctuation by influencing the proportion of high energy consumption, high-pollution industries and investment in clean equipment, green technology research and development. Therefore, it is necessary to use environmental regulation as the intrinsic incentive of industrial structure upgrading and to analyse the mechanism of environmental regulation to reduce economic fluctuation by forcing the industrial structure to upgrade; this is an important theoretical and practical research topic.

Research on the relationship between environmental regulation and industrial structure upgrading mainly focuses on two aspects. One aspect is the influence mechanism. Environmental regulation mainly influences the upgrading of the industrial structure by three means: demand, technological innovation and international trade transmission mechanism. The overall environmental regulation intensity of our country has a positive impact on the direction and path of industrial upgrading (Xiao Xingzhi, Li Shaolin; 2013). Li Qiang et al. (2013) [2] show that the existence of environmental regulation will increase the proportion of the service sector relative to the industrial sector and thus promote the adjustment of the industrial structure. The second aspect is empirical research. Li Xiaoying (2018) [3] uses the spatial econometric model to test the impact of environmental regulation on the industrial structure upgrading and finds that environmental 
regulation has a forced effect on industrial structure adjustment. However, this literature basically assumes that there is a linear relationship between environmental regulation and industrial structure upgrading. In fact, there is a threshold effect on the impact of environmental regulation on industrial structure upgrading. Zhong Maochu et al. (2015) [4] show that there is a U-type relationship between environmental regulation and industrial structure upgrading. Only when the threshold of environmental regulation is crossed can the adjustment of industrial structure be promoted.

Currently, there are great differences in the influence of different changes in the industrial structure on economic fluctuation. Dry Chunhui et al. (2011) [5] hold that the effects of rationalization and upgrading of the industrial structure on economic fluctuations are mainly manifested in unpredictable cyclical fluctuations; however, their influence mechanisms are quite different. Upgrading of the industrial structure is an important source of economic fluctuation, and the rationalization of the industrial structure is helpful to restrain economic fluctuation. Li Qiang (2012) [6] studies the relationship between industrial structure change and economic fluctuation through an econometric model. It is found that the change in the industrial structure is an important reason for economic fluctuation. Rationalization and upgrading of the industrial structure are helpful to alleviate economic fluctuation; however, the higher industrial structure has more influence on economic fluctuation than the rationalization of the industrial structure. Peng Chong et al. (2013) [7] use the panel vector autoregressive model to investigate the effect of an industrial structure change on economic fluctuation and determined that the rationalization of the industrial structure has an "ironing effect" on economic fluctuation; however, the impact of a high-level impact is strongly pro-cyclical. Both short and long term have obvious positive effects.

In summary, there is no literature on the relationship between environmental regulation, industrial structure and economic fluctuation, particularly on the direct effect of environmental regulation on economic fluctuation and the effect of industrial structure change. At the same time, the related research literature mainly utilizes provincial panel data to test the lack of industry-level environmental regulation, industrial structure upgrading and economic fluctuations; in addition, the industrial industry is the main body of our economy. This industry has an important effect on the economic fluctuation; therefore, it is necessary to examine and analyse the industrial industry. In addition, the most important item is the threshold effect of environmental regulation on industrial structure upgrading and economic fluctuation (Zhong Maochu et al., 2015 [4]). The existing static panel threshold technology ignores the dynamism and continuity of the explained 
variables and cannot address the endogenous problem of environmental regulation; therefore, there is much room for improvement.

Targeting the deficiency of the existing research, this paper mainly uses 35 industrial industries in China from 2003-2016 as the research object and uses dynamic panel threshold technology to directly test the direct effect between environmental regulation and economic fluctuation and the upgrading effect of the industrial structure. This paper provides the theoretical basis for establishing reasonable environmental regulation intensity to force the industrial structure to upgrade to reduce economic fluctuation and finally realizes the win-win situation between environmental protection and economic development. The contributions of this paper are as follows: First, environmental regulation, industrial structure upgrading and economic fluctuation are incorporated into the unified research framework, and the direct effect of environmental regulation on economic fluctuation and the upgrading effect of industrial structure are discussed. The second contribution is to extend the test to the industrial level. The third is to consider the dynamic nature of economic fluctuations, the continuity and the threshold effect, the use of dynamic panel threshold technology to estimate, and solving the endogenous problem of environmental regulation. The estimation conclusion is more robust.

\section{Research and design}

\subsection{Measurement model setting}

This paper mainly analyses the impact of environmental regulation on economic fluctuation through the upgrading of the industrial structure. Considering the dynamic and continuous nature of economic fluctuation and the endogenous nature of environmental regulation, the dynamic panel model is set as the basic model.

$$
V O L_{i t}=\beta_{0}+\varphi V O L_{i t-1}+\beta_{1} E R_{i t}+\beta_{2} E R_{i t} \times I S_{i t}+\beta_{3} I S_{i t}+\beta_{4} X_{i t}+\mu_{i}+v_{t}+\varepsilon_{i t}
$$

Among the variables, $i$ and $t$ represent the industry and the time, respectively; $\mu_{i}$ is the individual effect. $v_{t}$ is the time effect, and $\varepsilon_{i t}$ is the random disturbance term. $V O L_{i t}$ is the variable for economic fluctuation; it joins the lag period $V O L_{i t-1}$ to reflect the economic fluctuation dynamics, and the continuity, $E R_{i t}$ is environmental regulation and measures the direct effect on economic fluctuation. $I S_{i t}$ is the upgrading of the industrial structure, including 
the rationalization of the industrial structure $\left(I S R_{i t}\right)$ and the upgrading of the industrial structure $\left(I S S_{i t}\right)$. This paper also adds the cross item between the industrial structure and environmental regulation $\left(E R_{i t} \times I S_{i t}\right)$ to measure the indirect effect of environmental regulation on economic fluctuation through upgrading of the industrial structure. $X_{i t}$ is a control variable. Technological innovation $\left(T I_{i t}\right)$, human capital $\left(H U_{i t}\right)$, foreign direct investment $\left(F D I_{i t}\right)$, industry control variables $\left(I V_{i t}\right)$ and total factor productivity $\left(L P_{i t}\right)$ are selected to control the influence of related factors on economic fluctuation.

At the same time, considering that environmental regulation has a threshold effect on the industrial structure upgrading, and that there is a direct relationship between environmental regulation and economic fluctuation, this paper introduces threshold estimation based on the basic model and constructs a dynamic panel threshold estimation model to test it.

$$
V O L_{i t}=\gamma_{0}+\delta V O L_{i t-1}+\gamma_{1} E R_{i t} \times I(t h r \leq \lambda)+\gamma_{2} E R_{i t} \times I(t h r>\lambda)+\gamma_{3} X_{i t}+\mu_{i}+v_{t}+\varepsilon_{i t}
$$

where $I$ is the threshold function, $t h r$ is the threshold variables set, and $\lambda$ is for the corresponding threshold. This paper mainly establishes three threshold variables: technological innovation $\left(T I_{i t}\right)$, human capital $\left(H U_{i t}\right)$ and foreign direct investment $\left(F D I_{i t}\right)$. These variables are also the three intermediate variables (Xiao Xingzhi, Li Shaolin) that environmental regulation acts on in the upgrading of the industrial structure (2013); other variables are set as above.

\subsection{Variable selection and data sources}

In this paper, 35 industrial industries are the research object, and the time span is 2003-2016. The industry selection criteria are as follows. There are 39 double-digit industrial industries in the Yearbook of Industrial Economic Statistics of China, but considering that there are very few statistics on "other mining industries", the new "other mining industry" will be merged with the "non-metal ore mining and separation industry". Some data are missing from "handicraft and other manufacturing industries", "waste resources and waste materials recovery and processing industry" and "timber and bamboo harvesting and transportation industry". "Rubber products industry" and "plastic products industry" are merged into "rubber and plastic products industry" in "China Industry Statistics Yearbook 2013". This paper combines all the relevant data of "rubber 
products industry" and "plastic products industry" in previous years. The data are mainly from China Industry Statistics Yearbook, China Science and Technology Statistics Yearbook and China Environment Statistics Yearbook. The relevant variables are selected as follows:

1. Economic fluctuations. To measure macroeconomic fluctuation, there are mainly HP, BK and CF filters. However, in recent years, there have been many controversies in the HP filtering method. In this paper, the industrial added value of 35 industries in 2003-2016 is selected as the measurement index, and the CF filtering method is used to measure.

2. Environmental regulation. The environmental regulation measurement indexes mainly include the number of environmental laws and regulations and the sewage charge revenue; however, there is a lack of relevant data at the industry level. The proportion of operation cost in the total industrial output value of waste water and waste gas treatment in various industries is used as the proportion. The larger the proportion is, the greater the environmental regulation intensity is.

3. Upgrading of the industrial structure. According to relevant literature, industrial structure upgrading mainly includes rationalization and upgrading of the industrial structure, expressed by the structural deviation index (or Thiel index) and the ratio of tertiary industry output value to secondary industry output value (dry Chunhui et al., 2011 [5]). However, these indicators are difficult to apply to the industry level. This paper mainly refers to the practice of Zhang Bingbing and Zhu Jing (2015) [8] and uses the proportion of output value of each industrial industry in the gross output value of industrial industry as the substitute index for the rationalization of the industrial structure. At the same time, referring to the method of Fu Yuanhai et al. (2014) [9], we use the proportion of high-knowledge-complexity industries to the total industrial output value to measure the advanced industrial structure. Among these industries, high-knowledge and high-complexity industries include chemical raw materials and chemical products manufacturing, chemical fibre manufacturing, pharmaceutical manufacturing, general equipment manufacturing, special equipment manufacturing, transportation equipment manufacturing, electrical machinery and equipment manufacturing, communications equipment, computer and other electronic equipment manufacturing, instrumentation and culture, and office machinery manufacturing. After obtaining the annual data of the proportion of the industrial structure of the whole industry, the proportion of the added value of each industry in each industry is calculated. Then, the proportion of the industrial structure for each year is multiplied by the ratio of the industrial added value of the corresponding industry in that year, as the final representative of the industrial structure of the 
advanced variables of the index data.

4. Threshold variable. Technological innovation is expressed in terms of the proportion of internal expenditure of scientific and technological activities in each industry to the total industrial output value, and human capital is expressed in terms of the proportion of the number of scientific and technological activities in each industry to the total number of employees. With reference to Zhao Wenjun and Yu Jin-ping (2012) [10], foreign direct investment is expressed as the proportion of the total assets of industrial enterprises obtaining foreign investment and Hong Kong, Macao and Taiwan investment in the total assets of industrial industries above the scale.

5. Industry control variable. The industrial value-added rate is expressed by the ratio of the industrial added value to the industrial gross output value in the same period, and labour productivity is expressed by the ratio of industrial added value to the total number of employees.

\subsection{Dynamic panel threshold estimation method}

There is a fixed individual effect in the dynamic panel threshold model set in this paper, so it is necessary to eliminate the individual effect before estimating. Usually, there are two methods of intra-group transformation (within transformation) and first-order difference to deal with. However, in the dynamic panel threshold model, the delay of the explained variable is related to the mean value of the individual error term, so the estimation results of the intra-group transformation are no longer consistent. The first-order difference results in negative correlation of error terms, which cannot be directly applied to the threshold model proposed by Hasen. In this paper, referring to the method of Kremer et al. (2013) [11], the forward orthogonal deviation transform (the forward orthogonal deviations transformation) is used to eliminate the fixed effect in the dynamic panel model, targeting the deficiency of the intra-group transformation and the first-order difference method to eliminate the fixed effect in the dynamic panel model. This method is mainly used to subtract the average value of all the observed values from the observed value, and the error term after transformation no longer has the problem of sequence correlation. The forward orthogonal deviation transformation of model (2) is conducted, in which the forward orthogonal deviation transformation model of the error term is as follows:

$$
\varepsilon_{i t}^{*}=\sqrt{\frac{T-t}{T-t+1}} \bullet\left[\varepsilon_{i t}-\frac{1}{T-t}\left(\varepsilon_{i t+1}+\mathrm{L}+\varepsilon_{i T}\right)\right], t=1, \mathrm{~L}, T-1
$$

The forward orthogonal deviation transformation of other variables is consistent with the 
error term. Considering the strong endogeneity of model (2), this paper estimates the threshold of the dynamic panel with Caner and Hansen (2004) [12] in three steps.

\section{Empirical analysis}

\subsection{Panel unit root and cointegration test}

The premise of econometric estimation is that the variables are stable. This paper mainly uses the panel unit root test to test the stability of variables; this is mainly divided into the homogeneous unit root test (LLC test) and the heterogeneous unit root test (IPS test and Fisher-ADF test). Considering the comprehensiveness of the test, the homogeneous LLC test, the heterogeneous IPS test and the Fisher-ADF test are used as the main methods of the panel unit root test. At the same time, for stationary variables, the Kao cointegration test is also used to determine whether there is a long-term equilibrium relationship between variables. The original assumption is that there is no cointegration relationship. The test results shown in Table 2 show that the original sequences of the related variables are stable and can be tested by cointegration, while the Kao test rejects the original hypothesis that there is no cointegration relationship, with a level of $1 \%$ significance. It is shown that there is a long-term equilibrium relationship between variables, and the results of spatial measurement estimation are reliable.

Table1. Panel unit root and cointegration test results

\begin{tabular}{c|c|c|c}
\hline variable & LLC & IPS & Fisher-ADF \\
\hline VOL & $-16.922^{* * *}$ & $-5.562^{* * *}$ & $173.274^{* * *}$ \\
\hline ER & $-9.274^{* * *}$ & $-5.229^{* * *}$ & $151.236^{* * *}$ \\
\hline ISR & $-9.934^{* * *}$ & $-2.625^{* * *}$ & $109.890^{* * *}$ \\
\hline ISS & $-17.273^{* * *}$ & $-5.390^{* * *}$ & $112.232^{* * *}$ \\
\hline TI & $-9.339^{* * *}$ & $-2.519^{* * *}$ & $113.428^{* * *}$ \\
\hline HU & $-10.889^{* * *}$ & $-3.528^{* * *}$ & $102.007^{* * *}$ \\
\hline FDI & $-13.553^{* * *}$ & $-2.112^{* *}$ & $185.370^{* * *}$ \\
\hline IV & $-10.233^{* * *}$ & $-2.988^{* *}$ & \\
\hline LP & $-12.880^{* * *}$ & $-7.825^{* * *}$ & $-8.729^{* * *}$ \\
\hline KAO Test & & & \\
\hline
\end{tabular}


Note:

*The values in parentheses are the standard error statistics, presenting their significance at a level of $10 \%$.

** The values in parentheses are the standard error statistics, presenting their significance at a level of $5 \%$.

*** The value in parentheses are the standard error statistics, presenting their significance at a level of $1 \%$.

\subsection{Direct effect Test}

According to the established basic model, this paper first uses the dynamic panel estimation method to test the direct effect of environmental regulation on economic fluctuation and the upgrading effect of industrial structure. Considering the strong endogeneity of environmental regulation, the first order lag of environmental regulation is used as the tool variable to solve the endogeneity problem, and the robust estimation result is obtained using the system GMM two-step robust standard error estimation.

Table 2. Dynamic panel GMM estimation results

\begin{tabular}{|c|c|c|c|c|}
\hline \multirow{2}{*}{ variable } & \multicolumn{2}{|c|}{ Direct effect } & \multicolumn{2}{|c|}{ Industrial structure upgrading effect } \\
\hline & Rationalization & Advanced & Rationalization & Advanced \\
\hline \multirow{2}{*}{$\mathrm{VOL}_{\mathrm{t}-1}$} & $0.972^{* * *}$ & $0.968^{* * *}$ & $0.965^{* * *}$ & $0.975^{* * *}$ \\
\hline & (325.63) & (410.64) & (317.30) & $(314.25)$ \\
\hline \multirow{2}{*}{ ER } & $462.459^{* * *}$ & $466.942^{* * *}$ & $254.118^{* *}$ & 43.506 \\
\hline & $(6.40)$ & $(6.21)$ & $(2.50)$ & $(0.47)$ \\
\hline \multirow{2}{*}{$\mathrm{ER}^{2}$} & $-167.635^{* * *}$ & $-178.294^{* * *}$ & & \\
\hline & $(-5.59)$ & $(-5.65)$ & & \\
\hline ER & & & $-98.899^{* * *}$ & \\
\hline$\times$ ISR & & & $(-5.03)$ & \\
\hline ER & & & & $-109.99^{* * *}$ \\
\hline$\times$ ISS & & & & $(-2.61)$ \\
\hline \multirow{2}{*}{ ISR } & $-76.850^{* * *}$ & & $-37.410^{* *}$ & \\
\hline & $(-8.58)$ & & $(-2.41)$ & \\
\hline \multirow{2}{*}{ ISS } & & $-163.268^{* * *}$ & & $-158.231^{* * *}$ \\
\hline & & $(-17.47)$ & & $(-6.27)$ \\
\hline
\end{tabular}




\begin{tabular}{|c|c|c|c|c|}
\hline TI & $\begin{array}{c}-41.620^{* * *} \\
(-4.31)\end{array}$ & $\begin{array}{c}-10.684^{* * *} \\
(-3.32)\end{array}$ & $\begin{array}{c}-14.449^{* *} \\
(-1.98)\end{array}$ & $\begin{array}{c}-17.843^{*} \\
(-1.73)\end{array}$ \\
\hline $\mathrm{HU}$ & $\begin{array}{c}-43.713^{* * *} \\
(-10.79)\end{array}$ & $\begin{array}{c}-44.906^{* * *} \\
(-16.31)\end{array}$ & $\begin{array}{c}-39.243^{* * *} \\
(-18.27)\end{array}$ & $\begin{array}{c}-40.560^{* * *} \\
(-9.23)\end{array}$ \\
\hline FDI & $\begin{array}{c}-12.418^{* * *} \\
(-21.20)\end{array}$ & $\begin{array}{c}-13.042^{* * *} \\
(-19.41)\end{array}$ & $\begin{array}{c}-13.008^{* * *} \\
(-17.51)\end{array}$ & $\begin{array}{c}-14.274^{* * *} \\
(-21.83)\end{array}$ \\
\hline IV & $\begin{array}{c}-22.129^{* * *} \\
(-55.45)\end{array}$ & $\begin{array}{c}-18.855^{* * *} \\
(-38.79)\end{array}$ & $\begin{array}{c}-23.230^{* * *} \\
(-29.82)\end{array}$ & $\begin{array}{c}-21.530^{* * *} \\
(-46.02)\end{array}$ \\
\hline LP & $\begin{array}{l}-8.012^{* * *} \\
(-29.92)\end{array}$ & $\begin{array}{l}-8.195^{* * *} \\
(-34.02)\end{array}$ & $\begin{array}{l}-7.614^{* * *} \\
(-23.84)\end{array}$ & $\begin{array}{l}-7.749^{* * *} \\
(-28.57)\end{array}$ \\
\hline Shape & $\begin{array}{l}\text { Inverted } \\
\text { u-shaped }\end{array}$ & $\begin{array}{l}\text { Inverted } \\
\text { u-shaped }\end{array}$ & I & I \\
\hline $\begin{array}{l}\text { Point of } \\
\text { inflection }\end{array}$ & 1.379 & 1.309 & I & I \\
\hline Regional effect & yes & yes & yes & yes \\
\hline Time effect & yes & yes & yes & yes \\
\hline $\begin{array}{c}\text { Sargan } \\
\text { Test }\end{array}$ & $\begin{array}{l}31.347 \\
{[1.000]}\end{array}$ & $\begin{array}{l}31.041 \\
{[1.000]}\end{array}$ & $\begin{array}{l}29.858 \\
{[1.000]}\end{array}$ & $\begin{array}{l}29.996 \\
{[1.000]}\end{array}$ \\
\hline $\mathrm{AR}(1)$ & $\begin{array}{l}-2.131 \\
{[0.033]}\end{array}$ & $\begin{array}{l}-2.104 \\
{[0.035]}\end{array}$ & $\begin{array}{l}-2.072 \\
{[0.038]}\end{array}$ & $\begin{array}{l}-2.024 \\
{[0.043]}\end{array}$ \\
\hline $\operatorname{AR}(2)$ & $\begin{array}{c}0.596 \\
{[0.551]}\end{array}$ & $\begin{array}{c}0.687 \\
{[0.492]}\end{array}$ & $\begin{array}{c}0.499 \\
{[0.618]}\end{array}$ & $\begin{array}{c}0.535 \\
{[0.592]}\end{array}$ \\
\hline
\end{tabular}

Note:

$*$ The values in parentheses are standard error statistics, presenting their significance at a level of $10 \%$.

** The values in parentheses are standard error statistics, presenting their significance at a level of $5 \%$.

$* * *$ The values in parentheses are standard error statistics, presenting their significance at a level of $1 \%$.

The estimation results show that the Sargan test results all accept the original hypothesis that the tool variables are valid, which indicates that the tool variables are set reasonably, and the AR (2) test results show that there is no second-order sequence correlation. The lag first-order coefficient of economic fluctuation is above 0.95 , which indicates that the dynamic panel model is reasonable. From the direct effect estimation of environmental regulation and economic 
fluctuation, the coefficient of environmental regulation, ER, is significantly positive, and the square term is significantly negative in both the industrial structure rationalization and the industrial structure advanced model. The result shows that there is an inverted "U"-type relationship between environmental regulation and economic fluctuation. With the enhancement of environmental regulation, economic fluctuation first increases and then decreases. When the environmental regulation is lower than the specific threshold, the increase of the non-productive environmental cost in the short term will urge enterprises to reduce their investment, but the main body of the investment decline consists of enterprises with poor pollution control equipment and serious pollution. When the environmental regulation is further raised beyond the threshold, polluting enterprises will be gradually "cleaned", and the green innovation ability of the industry will be continuously improved. Once the innovation investment income exceeds the cost, the whole industry will choose to increase the innovation investment, thus improving the overall level of investment. Therefore, there is a direct " $U$ " relationship between environmental regulation and investment. At the same time, the impact on economic growth is also obvious; when investment decreases, economic volatility increases. When investment increases, particularly when the level of innovation investment increases, it will promote steady economic growth and reduce economic volatility. Therefore, the relationship between environmental regulation and economic fluctuation also shows a direct "U"-type relationship.

From the perspective of the upgrading effect of environmental regulation on the industrial structure of economic fluctuation, although the coefficient of environmental regulation ER is significantly positive (in the industrial structure rationalization model) or not (in the industrial structure advanced model). However, the cross term ER $\times$ ISR,ER $\times$ ISS with the rationalization of industrial structure or the upgrading of industrial structure is significantly negative, which indicates that the enhancement of environmental regulation is conducive to promoting the upgrading of industrial structure and reducing economic fluctuations. When the environmental regulation is strengthened, the cost of the pollution industry rises. Subsequently, some seriously polluted enterprises incrementally withdraw from the market. The resources flow to the clean industry, which is conducive to the optimization and upgrading of the industrial structure, to promote the steady growth of the economy and to reduce the economic fluctuation in the long run. The coefficients of industrial structure rationalization ISR and industrial structure advanced ISS are both significantly negative, which indicates that the two forms of industrial structure upgrading are beneficial to reduce the economic fluctuation. The optimization of industrial 
structure is conducive to promoting the long-term and healthy development of economy and will increase the stability of the economy, which is in line with the economic reality. In terms of controlling variables, both technological innovation and human capital are conducive to reducing economic fluctuations. Both technological innovation and human capital are important supporting factors for long-term economic growth and have "ironing effect" on economic fluctuations. The advanced technology management experience brought by FDI and the technology spillover effect can promote the technological progress of the host country, and then promote the economic growth and reduce the economic fluctuation. In addition, the industrial value added rate (IV) and labour productivity LP (LP) show that the improvement of economic efficiency and development quality can promote the reduction of economic fluctuation.

\subsection{Threshold effect test}

\section{Threshold estimation and significance test.}

According to the results of the threshold estimation and the significance test, if TI is used as the threshold variable, there is only one threshold value in both the industrial structure rationalization model and the industrial structure advanced model. In the industrial structure rationalization model, the threshold is the technological innovation level of 1.35, while in the industrial structure advanced model, the threshold is the technological innovation level of 1.26. By calculating the average value of the technological innovation water for 35 industrial industries between 2003 and 2015, it was found that the industries that crossed the $1.35 \%$ threshold were mainly medicine $(1.76 \%)$, manufacturing of specialized equipment $(1.64 \%)$, manufacturing of transportation equipment $(1.60 \%)$, manufacturing of communications equipment, computers and other electronic equipment $(1.59 \%)$, manufacturing of instruments and cultural office machinery $(1.55 \%)$, and electrical machinery and equipment manufacturing industry $(1.46 \%)$, a total of 6 industries. The other 29 industries did not cross the threshold level of technological innovation. In addition to the six sectors above the 1.26 percent threshold, there is the general equipment manufacturing industry (1.26 percent) for a total of seven industries. In addition, according to figs. 1 and 2, a single threshold exists, which indicates that environmental regulation has a technological innovation threshold for industrial structure upgrading and economic fluctuation.

Table 3. Threshold estimation and significance test results

\begin{tabular}{c|c|c|c|c|c|c|c|c}
\hline \multirow{2}{*}{ Model } & $\begin{array}{c}\text { Threshold } \\
\text { variable }\end{array}$ & Threshold & $\mathrm{F}$ & $10 \%$ & $5 \%$ & $1 \%$ & $\begin{array}{c}\text { threshold } \\
\text { value }\end{array}$ & $\begin{array}{c}95 \% \text { confidence } \\
\text { interval }\end{array}$ \\
\hline \multirow{2}{*}{ Rationalization } & \multirow{2}{*}{ TI } & single & $21.010^{* *}$ & 15.529 & 18.520 & 23.844 & 1.350 & {$[1.240,1.380]$} \\
\cline { 3 - 9 } & & double & 13.030 & 16.445 & 20.604 & 29.510 & 0.140 & {$[0.110,0.140]$} \\
\cline { 3 - 9 } & HU & single & 8.730 & 15.846 & 20.730 & 26.538 & 3.090 & {$[2.790,3.110]$} \\
\hline
\end{tabular}




\begin{tabular}{c|c|c|c|c|c|c|c|c}
\hline & FDI & single & 29.460 & 32.083 & 36.953 & 46.877 & 58.630 & {$[57.520,59.090]$} \\
\hline \multirow{4}{*}{ Advanced } & \multirow{2}{*}{ TI } & single & $23.080^{* *}$ & 16.152 & 19.303 & 34.260 & 1.260 & {$[1.205,1.270]$} \\
\cline { 2 - 8 } & & double & 13.300 & 18.036 & 22.247 & 28.780 & 0.140 & {$[0.110,0.140]$} \\
\cline { 2 - 8 } & HU & single & 12.370 & 16.595 & 18.420 & 27.905 & 4.480 & {$[4.330,4.490]$} \\
\cline { 2 - 8 } & FDI & single & 26.140 & 36.958 & 43.190 & 60.853 & 58.630 & {$[26.220,59.090]$} \\
\hline
\end{tabular}

Note:

** The values in parentheses are standard error statistics, presenting their significance at a level of $5 \%$.

If human capital $\mathrm{HU}$ is used as the threshold variable, in both the industrial structure rationalization model and the industrial structure advanced model, the significance test results show that there is no threshold effect. The result shows that the enhancement of industry environmental regulation will not restrict the level of human capital or the influence of human capital on the upgrading of industrial structure and the fluctuation of the economy. Alternatively, the finding shows the restriction of human capital on this kind of effect is relatively small, which is not sufficient to constitute a threshold. At the same time, if FDI is used as the threshold variable, the significance test results of the threshold effect in the two models also show that there is no threshold effect; this indicates that the enhancement of industry environmental regulation does not restrict FDI on the upgrading of the industrial structure and the impact of economic fluctuation. Alternatively, FDI has less restriction on this effect and is not sufficient to form a threshold. In fact, the key to the impact of environmental regulation on the upgrading of the industrial structure and on the economic fluctuation is whether the innovation investment income caused by the enhancement of environmental regulation is greater than the cost, thus affecting the innovation investment choice and the investment level improvement in the whole industry. All of these impacts depend on the level of technological innovation in the industry, but when the level of technological innovation is low, it is difficult to promote the innovation investment income to exceed the cost through environmental regulation. However, only the industry that surpasses the threshold has better technical innovation strength. When the environmental regulation strengthens, these enterprises will raise income through innovation investment; once this exceeds the cost, it will raise the investment level of the whole industry. Therefore, it is not difficult to understand why the impact of environmental regulation on the upgrading of the industrial structure is only the threshold of technological innovation and not the threshold of human capital and FDI. 


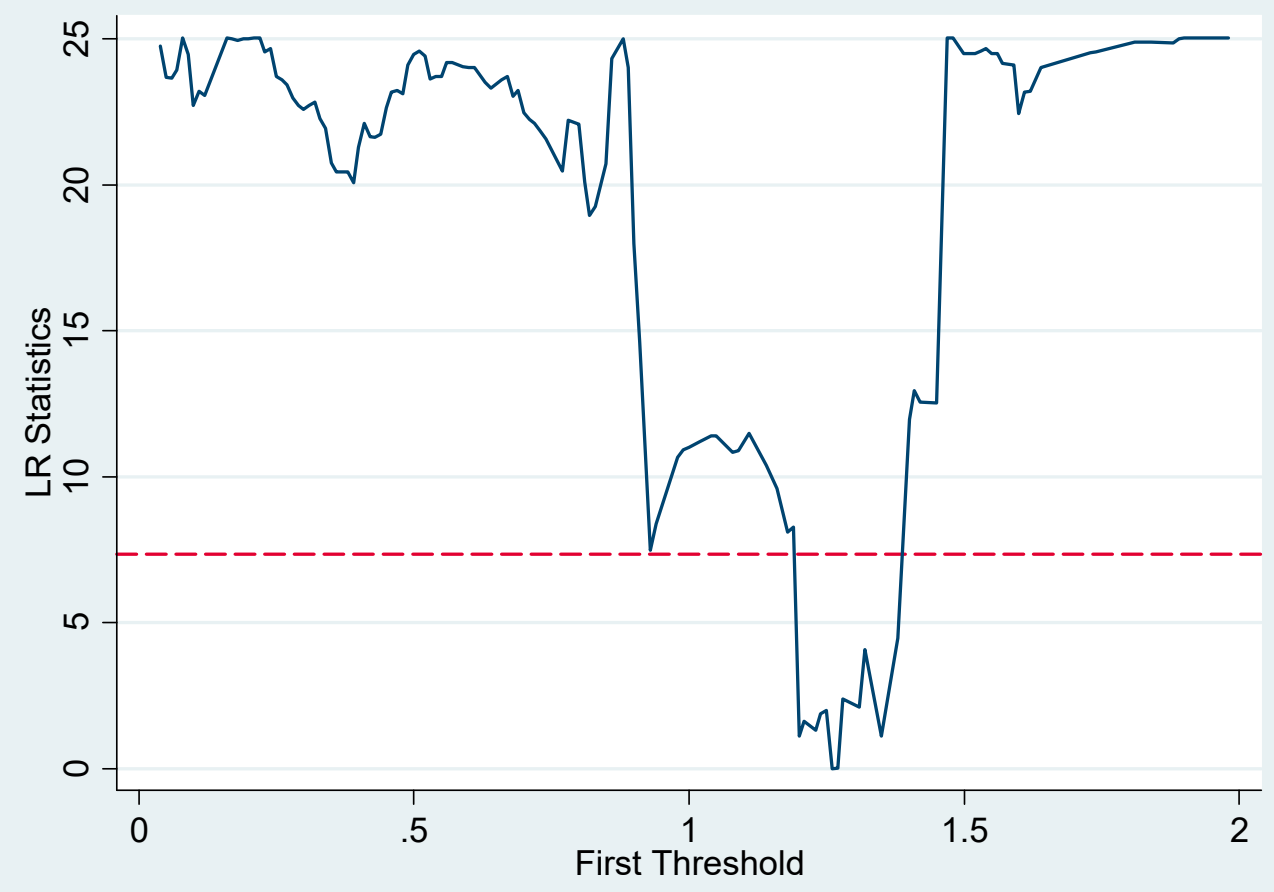

Figure 1. Threshold and confidence interval of technological Innovation as threshold variable(Industrial structure rationalization model)

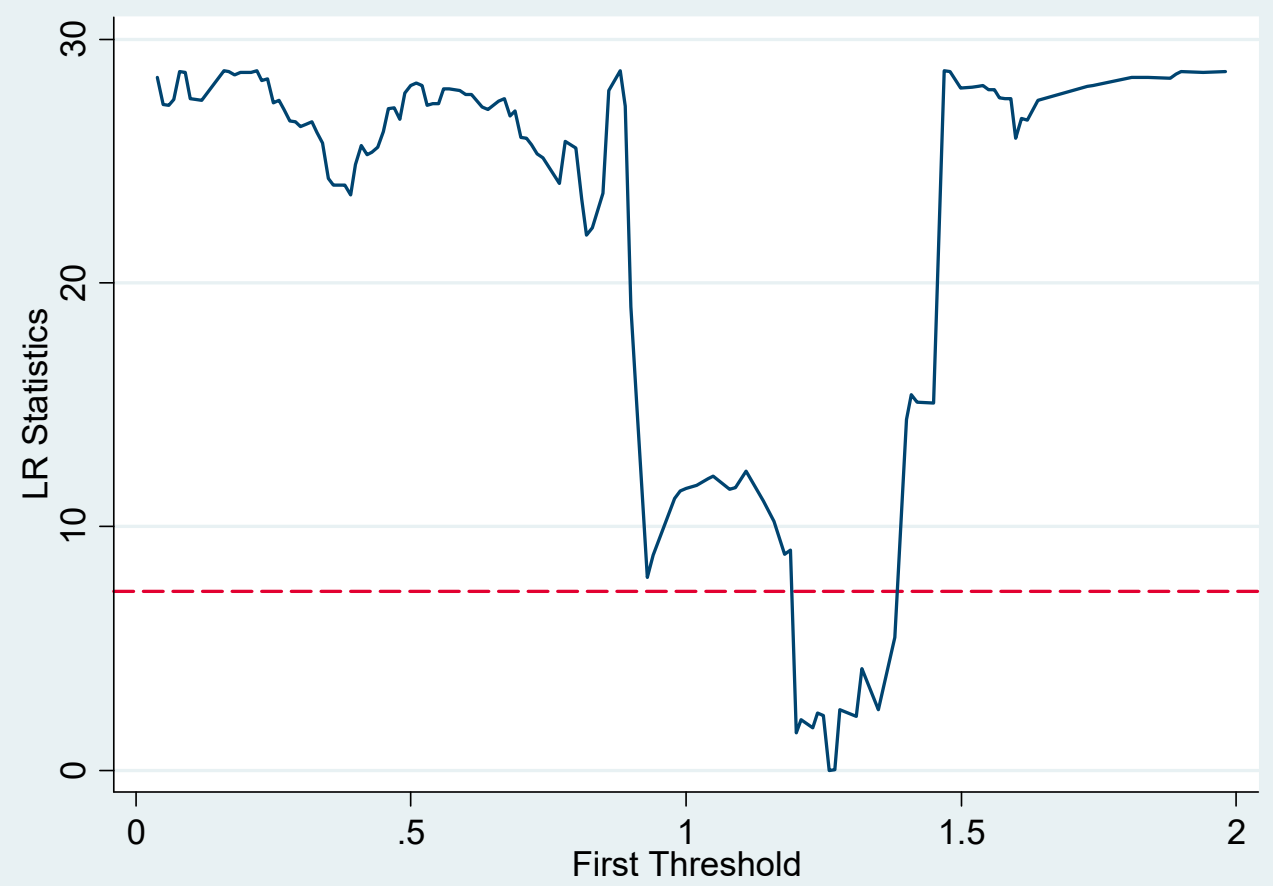


Figure 2. Threshold and confidence interval of technological Innovation as threshold variable(Advanced industrial structure model)

2. Dynamic panel threshold estimation results.

In this paper, upgrading of the industrial structure is divided into rationalization and upgrading, and the corresponding threshold TI is $1.35 \%$ (rationalization) and $1.26 \%$ (advanced). This paper uses the lag of environmental regulation more than one order as the tool variable to solve the endogenous problem and uses the dynamic panel GMM two-step robust standard to test the threshold effect of environmental regulation and industrial structure upgrading on economic fluctuation. In the estimates shown in tables 5 and 6, the Sargan test results show that the tool variables are set reasonably, and the AR (2) test shows that there is no second order sequence correlation. In addition, the lag first order coefficient of economic fluctuations is above 0.90 and significant; this shows that the economic fluctuation is dynamic.

From the estimation model of environmental regulation, industrial structure rationalization and economic fluctuation, the coefficients of the main variables are different when $\mathrm{TI} \leq 1.35 \%$ and TI $>1.35 \%$. One is the direct effect. When $\mathrm{TI} \leq 1.35$, the coefficient of ER of environmental regulation is not significant, and the coefficient of the quadratic term is not significant, which indicates that the promoting effect of environmental regulation on reducing economic fluctuation is not obvious. However, when TI $>1.35$, the coefficient of ER of environmental regulation is significantly negative, and the coefficient of the quadratic term is significantly positive, which indicates that there is a direct " $U$ " type relationship between environmental regulation and economic fluctuation. With the enhancement of environmental regulation, the economic fluctuation decreases first and then increases. The corresponding inflection point is the level of environmental regulation, 2.398. However, by calculating the environmental regulation level of each industry from 2003 to 2015, it is found that the industry has not crossed this threshold. Therefore, when $\mathrm{TI}>1.35 \%$, environmental regulation is strengthened, and the economic fluctuation can be reduced. This finding is also consistent with the previous analysis. When the level of technological innovation is high, the enhancement of environmental regulation is conducive to stimulate industry innovation investments, improve the overall investment level, maintain the steady development of the economy, and reduce economic fluctuations. Second, with the upgrading effect of the industrial structure, when $\mathrm{TI} \leq 1.35$, the first and cross terms of environmental regulation are not significant; this indicates that the enhancement of environmental 
regulation has not forced the upgrading of the industrial structure, thus reducing economic fluctuations. However, when $\mathrm{TI}>1.35$, environmental regulation can promote the reduction in economic fluctuation; at the same time, it can indirectly reduce economic fluctuations by forcing the upgrading of the industrial structure. This finding is confirmed by the negative coefficients of the first term and cross term of ER. Similarly, when the level of environmental regulation and the level of technological innovation exceed a certain threshold, the rising cost of environmental standards leads to the transfer of labour and capital to clean industries, which is conducive to optimizing the industrial structure, promoting economic development, and reducing economic volatility. Furthermore, the coefficient of rationalization of industrial structure is significantly negative in both models, which indicates that rationalization of the industrial structure is beneficial to reducing economic fluctuations, which is consistent with the previous analysis. The coefficient and significance of other variables are consistent with the previous analysis and are not discussed here.

Table 4. Dynamic panel threshold estimation results(Rationalization of industrial structure)

\begin{tabular}{|c|c|c|c|c|}
\hline \multirow{2}{*}{ variable } & \multicolumn{2}{|c|}{ Direct effect } & \multicolumn{2}{|c|}{ Industrial structure upgrading effect } \\
\hline & $\mathrm{TI} \leq 1.35 \%$ & $\mathrm{TI}>1.35 \%$ & $\mathrm{TI} \leq 1.35 \%$ & $\mathrm{TI}>1.35 \%$ \\
\hline ER & $\begin{array}{c}-2998.277 \\
(-0.79)\end{array}$ & $\begin{array}{c}-263.093^{* * *} \\
(-7.90)\end{array}$ & $\begin{array}{c}-37947.050 \\
(-1.20)\end{array}$ & $\begin{array}{c}-114.012^{*} \\
(-1.67)\end{array}$ \\
\hline $\mathrm{ER}^{2}$ & $\begin{array}{c}1498.876 \\
(0.41)\end{array}$ & $\begin{array}{c}54.848^{* * *} \\
(4.67)\end{array}$ & & \\
\hline $\begin{array}{c}\text { ER } \\
\times \text { ISR }\end{array}$ & & & $\begin{array}{c}6681.612 \\
(1.10)\end{array}$ & $\begin{array}{c}-59.505^{* * *} \\
(-8.17)\end{array}$ \\
\hline $\mathrm{VOL}_{\mathrm{t}-1}$ & & & & \\
\hline ISR & & & & \\
\hline TI & & & & \\
\hline $\mathrm{HU}$ & & & & \\
\hline
\end{tabular}




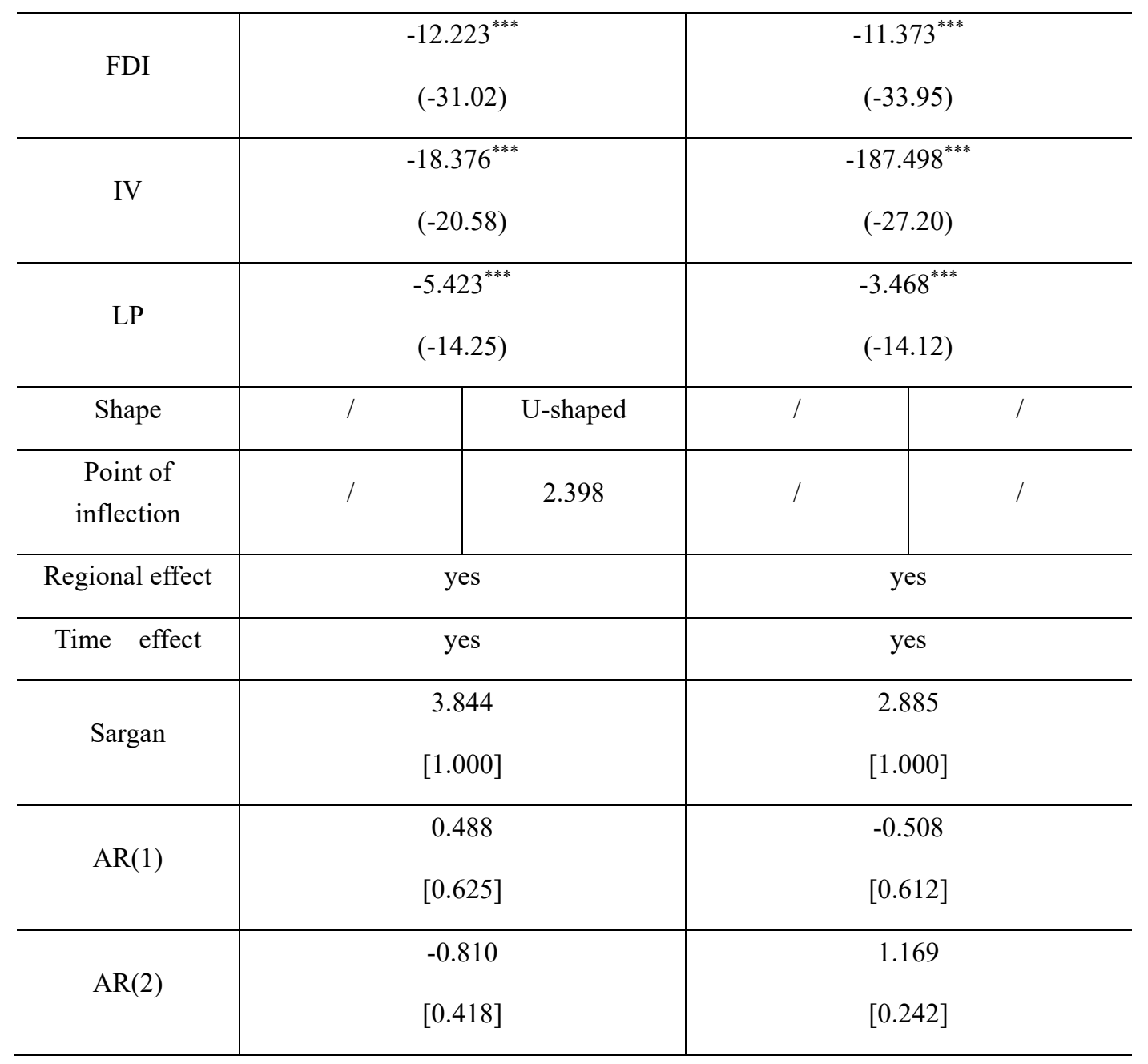

Note:

$*, * *$ and ${ }^{* * *}$ mean $1 / 5 \%$ and $10 \%$ significant level reject the original hypothesis. In parentheses are $Z$ values of statistics and $P$ values of statistics in square brackets.

From the estimation model of environmental regulation, advanced industrial structure and economic fluctuation, the influence coefficient of the main variables is obvious when $\mathrm{TI} \leq 1.26 \%$ and $\mathrm{TI}>1.26 \%$. One is the direct effect. When $\mathrm{TI} \leq 1.26$, the coefficient of ER of environmental regulation is negative but not significant, and the coefficient of quadratic term is not significant, which indicates that the promoting effect of environmental regulation on reducing economic fluctuation is not obvious. However, when TI $>1.26$, the coefficient of environmental regulation ER is significantly negative, and the quadratic coefficient is significantly positive, which reflects again that there is a "U"-type relationship between environmental regulation and economic fluctuation. When environmental regulation is increasing, the economic fluctuation decreases first 
then increases. The corresponding inflection point is the level of environmental regulation, 1.781. In sum, only the production and supply of electricity and heat can be divided into environmental regulation levels in a few years. However, the other industries have not leapfrogged, which indicates that an increase in environmental regulation over $1.26 \%$ of TI is beneficial to reducing the economic fluctuation. The second is the upgrading effect of industrial structure. When $\mathrm{TI} \leq$ 1.26 , the first item of environmental regulation is not significant; however, the coefficient of the cross item is significantly negative, which is very different from the industrial structure rationalization model, which indicates that the enhancement of environmental regulation can promote the upgrading of the industrial structure to a certain extent. Then, we reduce the economic fluctuation. When TI $>1.26$, the primary and cross terms of environmental regulation are significantly negative, which indicates that environmental regulation can promote the reduction in economic fluctuations and indirectly reduce economic fluctuations by promoting the upgrading of the industrial structure. In general, when the level of technological innovation is high, the enhancement of environmental regulation plays a more important role in upgrading the industrial structure, promoting labour and capital flow to the complex industries with high knowledge. Undoubtedly, it is advantageous to promote the upgrading of the industrial structure and reduce economic fluctuations. In addition, the effect of the coefficient of industrial structure upgrading on reducing economic fluctuation is obviously larger than that of industrial structure rationalization, which indicates that the contribution of industrial structure upgrading to reducing economic fluctuation is greater, and the estimated coefficients of other variables are basically consistent with the previous ones.

Table5. Dynamic panel threshold estimation results(Advanced industrial structure)

\begin{tabular}{c|c|c|c|c}
\hline \multirow{2}{*}{ variable } & \multicolumn{2}{|c|}{ Direct effect } & \multicolumn{2}{c}{ Industrial structure upgrading effect } \\
\cline { 2 - 5 } & $\mathrm{TI} \leq 1.26 \%$ & $\mathrm{TI}>1.26 \%$ & $\mathrm{TI} \leq 1.26 \%$ & $\mathrm{TI}>1.26 \%$ \\
\hline \multirow{2}{*}{$\mathrm{ER}$} & -442.090 & $-352.346^{* * *}$ & 48101.090 & $-155.982^{* * *}$ \\
& $(-0.06)$ & $(-9.34)$ & $(1.60)$ & $(-3.25)$ \\
\hline $\mathrm{ER}^{2}$ & -2669.195 & $98.916^{* * *}$ & & \\
\hline $\mathrm{ER}$ & $(-0.29)$ & $(7.36)$ & & $-22240.520^{*}$ \\
$\times \mathrm{ISS}$ & & & $(-1.73)$ & $(-2.57)$ \\
\hline VOL & \multicolumn{2}{|c|}{$0.968^{* * *}$} & & \multicolumn{2}{c}{$0.910^{* * *}$} \\
\hline
\end{tabular}




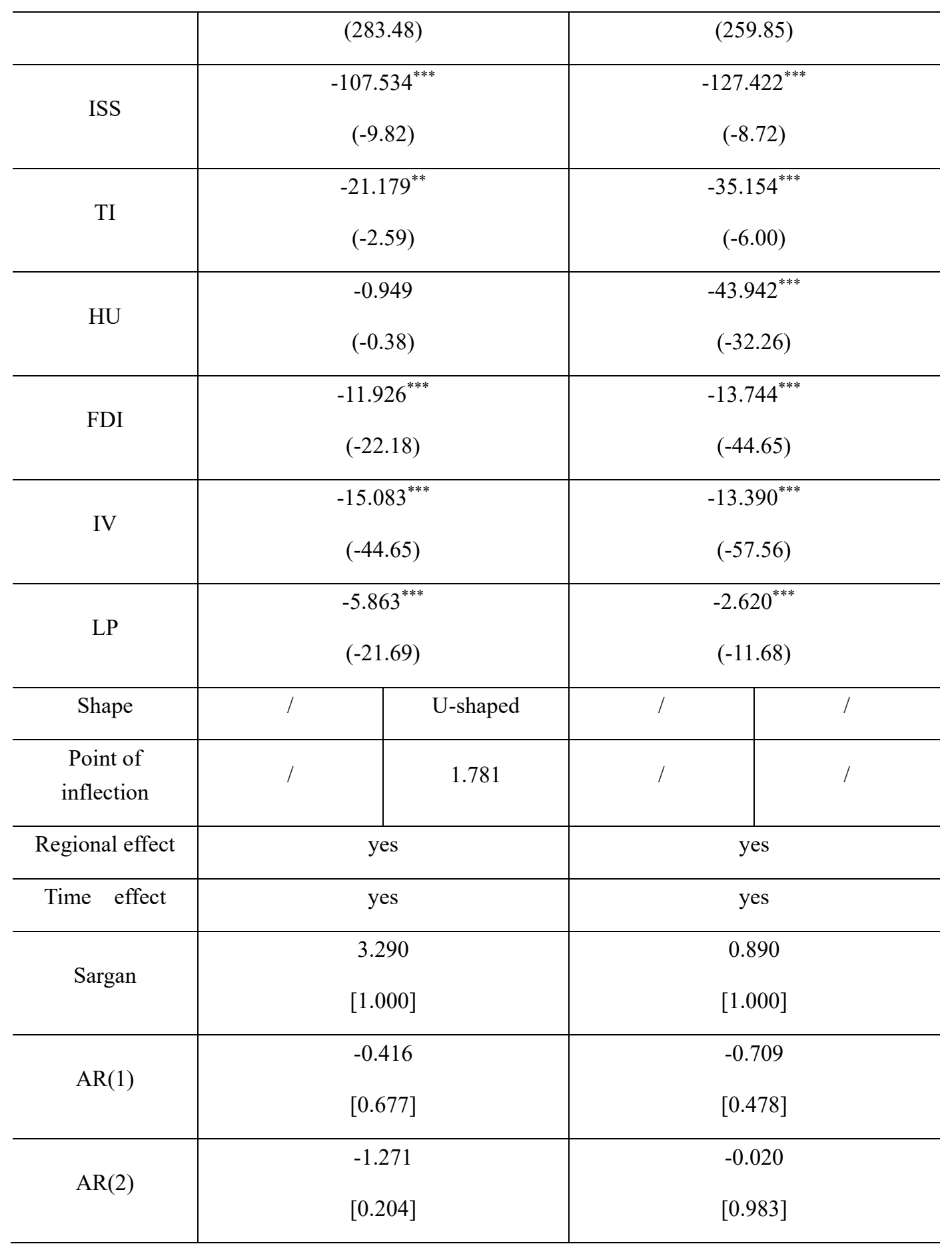

Note:

$*, * *$ and ${ }^{* * *}$ mean $1 / 5 \%$ and $10 \%$ significant level reject the original hypothesis. In parentheses are $Z$ values of statistics and $P$ values of statistics in square brackets.

\section{Research conclusions and policy implications}


Currently, China's economy and society have entered the "new normal" of speedy shifts and structural adjustment. How does the country upgrade its industrial structure under steady economic fluctuation? In addition, how does the country reduce economic fluctuations through upgrading the industrial structure is an important problem confronting our country. In this paper, environmental regulation is used as the intrinsic incentive for upgrading the industrial structure, and 35 industrial industries in China from 2003 to 2016 are used as the research object. The direct effect between environmental regulation and economic fluctuation and the upgrading effect of industrial structure are examined directly by using dynamic panel threshold technology, which provides a theoretical basis for setting a reasonable environmental regulation intensity to force industrial structure upgrading to reduce economic fluctuation. The main conclusions are as follows:

1. The conclusions are as follows: (1) There is an inverted "U"-type relationship between environmental regulation and economic fluctuation, which is accompanied by the enhancement of environmental regulation. Economic fluctuation increases first then decreases. (2) The cross terms between environmental regulation and rationalization of the industrial structure or upgrading the industrial structure are significantly negative, indicating the enhancement of environmental regulation. It is beneficial to promote the upgrading of the industrial structure and reduce economic fluctuation. (3) The coefficients of industrial structure rationalization and industrial structure upgrading are all significantly negative, indicating that both forms of industrial structure upgrading are conducive to reducing economic fluctuations.

2. Conclusion of dynamic panel threshold model. (1) Environmental regulation has a technological innovation threshold for industrial structure upgrading and economic fluctuation; however, there is no human capital threshold or FDI threshold. (2) In the industrial structure rationalization model, when $\mathrm{TI} \leq 1.35$, the effect of environmental regulation on reducing economic fluctuation is not obvious, but when TI $>1.35$, there exists a direct "U" relationship between environmental regulation and economic fluctuation, which is accompanied by the enhancement of environmental regulation. The economic fluctuation decreases first then increases, and the corresponding inflection point is the level of environmental regulation, 2.398. When $\mathrm{TI} \leq$ 1.35 , the enhancement of environmental regulation does not force the upgrading of the industrial structure to reduce economic fluctuations, but when TI > 1.35, environmental regulation can promote a reduction in economic volatility. At the same time, environmental regulation can indirectly reduce the economic fluctuation by forcing the upgrading of the industrial structure. (3) 
In the advanced model of industrial structure, when $\mathrm{TI} \leq 1.26$, the promoting effect of environmental regulation on reducing economic fluctuation is not obvious. However, when TI > 1.26, there is a "U" relationship between environmental regulation and economic fluctuation. When environmental regulation is strengthened, economic fluctuation decreases first then increases. The corresponding inflection point is the environmental regulation level of 1.781. When $\mathrm{TI} \leq 1.26$, the enhancement of environmental regulation can promote the upgrading of the industrial structure then reduce the economic fluctuation; however, when TI $>1.26$, environmental regulation can promote the reduction of economic fluctuation. At the same time, environmental regulation can indirectly reduce economic fluctuations by promoting the upgrading of the industrial structure.

In conclusion, on the one hand, we should establish different environmental regulation level for different industries. We should strengthen the environmental regulation for the industry without crossing the inflection point value, enrich the environmental regulation means on the basis of maintaining the existing environmental regulation level for the industry that has crossed the inflection point value, and encourage innovative investment through policy combination. We should also promote the transfer of labour and resources to clean industries and high-tech industries, optimize the industrial structure, promote steady economic growth, and reduce fluctuations. (2) We should increase investment in technological innovation, particularly in industries that do not cross the threshold of technological innovation. Through preferential policies to improve the investment in technological innovation, we can improve the level of technological innovation in these industries. On the basis of reasonable investment in technological innovation, we should optimize the structure to improve efficiency, promote the advanced development of the industrial structure and reduce economic fluctuation for industries with high knowledge complexity.

\section{Disclosure statement}

The authors declare no conflict of interest

\section{Reference}

[1]Xiao Xingzhi, Li Shaolin. Dynamic Impacts of Environmental Regulation of Industrial Upgrading Path [J]. Economic Theory and Economic Management,2013(6):102-112. 
[2]Li Qiang et al. Environmental Regulation and Industrial Structure Adjustment: The Theoretical Analysis and Empirical Study Based on Baumol Model [J]. Economic Review,2013(5):100-107.

[3]Li Xiaoying. FDI, Environmental Regulation and Industrial Structure Optimization: An Empirical Evidence Based on Spatial Econometrics Model [J]. Modern Economic Science,2018(3):104-113.

[4]Zhong Maochu, et al.Can Environmental Regulation Force Industrial Structure Adjustment:

An Empirical Analysis Based on Provincial Panel Data [J]. China's Population, Resources and Environment,2015(8):107-115.

[5]Gan Chunhui, et al.An Empirical Study on the Effects of Industrial Structure on Economic Growth and Fluctuations in China [J]. Economic Research Journal,2011(5):4-16.

[6]Li Qiang. Industrial Structure Change Aggravate or Restrain Economic Fluctuations [J]. Economic and Management Studies,2012(7):29-37.

[7]Peng Chong et al.Study on the Dynamic Effects of Industrial Structure on Economic Fluctuation [J]. Industrial Economy Research,2013(3):91-100.

[8]Zhang Bingbing, Zhu Jing. Study on Influence of Export on Total Factor Energy Efficiency: An

Empirical Analysis from Perspective of 37 Industrial Sectors in China[J]. International Trade Issues,2015(4):56-65.

[9]Fu Yuanhai, et al. The Selection of Technology Progress Path of Manufacturing Structure Optimization-An Empirical Analysis Based on Dynamic Panel Data Model [J]. China's Industrial Economy,2014(9):78-90.

[10]Zhao Wenjun, Yu Jin-ping. Trade Openness, FDI and China's Industrial Economic Growth Pattern:Empirical Analysis Based on Data of 30 Industrial Sectors [J]. Economic Research Journal,2012(8):18-31.

[11]Kremer S.,A. Bick,D.Nautz.Inflation and Growth:New Evidence from a Dynamic Panel Threshold Ana1ysis[J].Empirical Economics,2013(44):1-18.

[12]Mehmet Caner,Bruce E.Hansen.Instrumental Variable Estimation of a Threshold Model[J].Econometric Theory,2004(20):813-843. 